\title{
Shimao and Erlitou: new perspectives on the origins of the bronze industry in central China*
}

\author{
J. Rawson**
}

Over the last five years, excavation of a large, stone, fortified site at Shimao, on the northern edge of the Loess Plateau in Shaanxi Province, China, has radically changed our understanding of the events that precipitated the development of the first bronze casting in central China at Erlitou (Figure 1). An international conference on the Shimao site, held at Shenmu in August 2016, explored many aspects of this major discovery.

The Shimao site, on a hilltop in the Loess Plateau, south-east of the Ordos region, covers 400ha. It comprises two walled areas, inner and outer, with substantial gates and a large central construction thought to be a ritual or palace site (Figure 2). The excavators, the Shaanxi Provincial Archaeological Institute led by Sun Zhouyong, regard Shimao as a city. Several pits containing skulls have been excavated and radiocarbon-dated to between 2300 and 1800 BC (Figure 3). Neolithic-period ceramics of Longshan type, including tripods and steamers suitable for boiling and steaming millet, are congruent with this dating.

While the stone walls and jades found in the area have been known for many decades, the region was not fully explored until recently. Shimao is the largest site in the area and clearly a dominant centre, but it was by no means isolated, with 11 walled, and over 190 unwalled, sites found nearby (Shaanxi 2016). Additional walled sites have now been explored (Figure 1), extending to Yulin and as far south as Luliang on both sides of the Yellow River (Wang \& Zhang 2016: fig. 9).

Shimao's significance is twofold. First of all, a previously unrecognised Neolithic community has been identified with many unusual practices, including, most notably, largescale stone fortifications_-implying a competitive or even hostile social environment—and the presence of bronze knives, arrowheads and ornaments, comparable with those of similar periods in the steppe, alongside jade and Longshan-type pottery, with strong links to wider, central-Chinese Neolithic developments. Secondly, the site and the associated areas with similar stone fortified centres were evidently important links between the peoples of the steppe, in present-day Inner Mongolia and farther north, and the much better-known large sites at Taosi and Erlitou, regarded as the founding centres of China's Bronze Age culture (Figure 1).

* Figures 2, 3 and 4 have been replaced, and their captions amended from the originally published article. A correction notice has been published online https:// doi.org/10.15184/ aqy.2017.34

** School of Archaeology, University of Oxford, 34-36 Beaumont Street, Oxford OX1 2PG, UK (Email: jessica.rawson@merton.ox.ac.uk) 


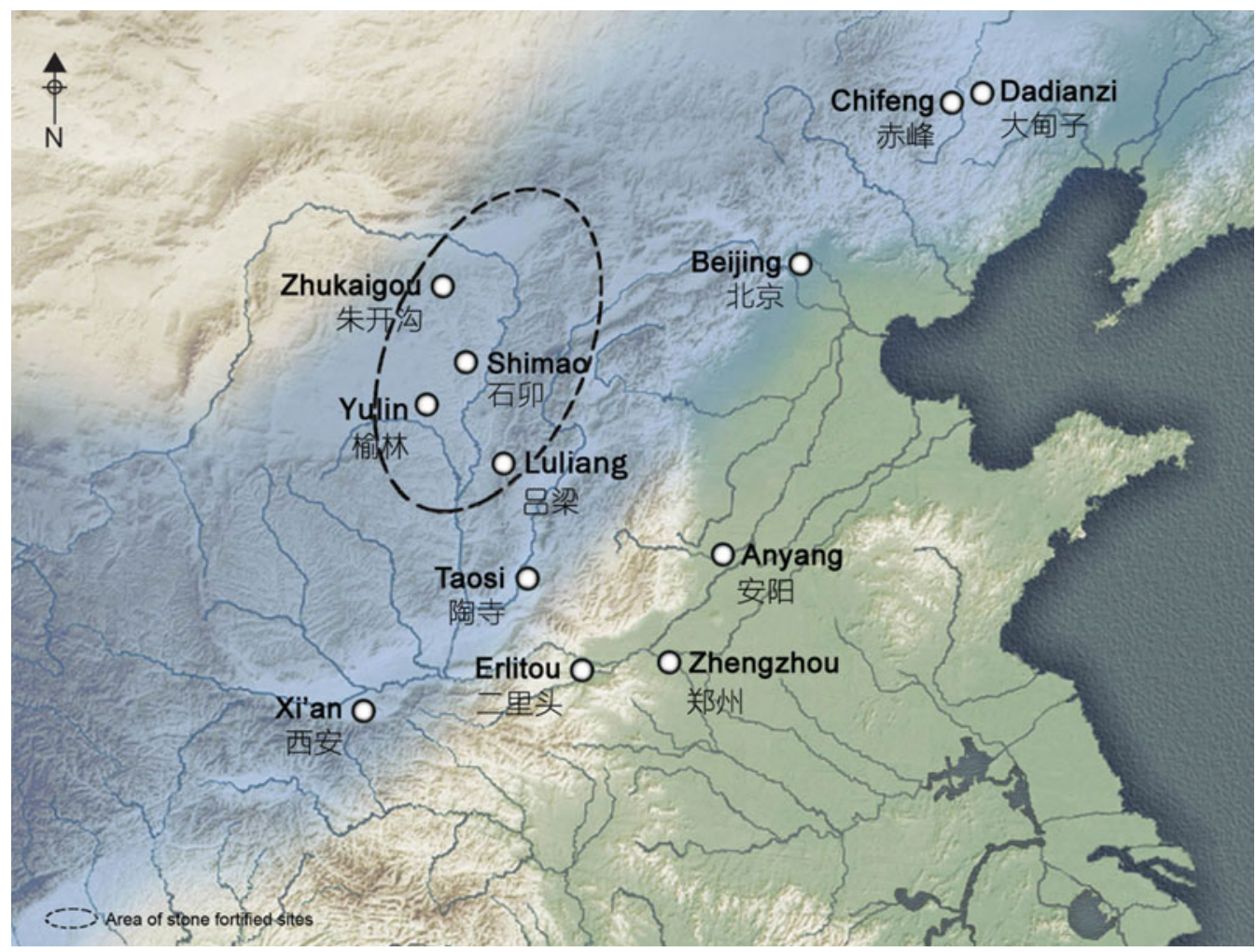

Figure 1. Map of northern China and the steppe, showing the sites named in the paper. The shaded area is an intermediate zone between the steppe and central China. The dotted line encircles a region with stone fortified sites. Map by Beichen Chen.

In these wider relationships, climate change played a significant role. Large increases in the number of settlements in the region in the fourth to third millennia BC indicate a propitious climate, while domesticated animals, such as sheep and goats, may have been brought there by people from the north moving south (Hu et al. 2008). Bronze Age sites in the region, post-dating Shimao, illustrate a sharp decline in population, as a cold dry spell took over (Zhang et al. 1999; Liu et al. 2014; Peng et al. 2015). Telling examples of closely related bronzes and jades have been found farther south, at Taosi (Taosi 2015: vol. 4, pls 39-53) and Erlitou, suggesting that some of the populations of Shimao or of the other stone fortified sites moved there, taking both bronzes and jades with them.

It has long been known that a single-edged knife found at Erlitou, the centre of the first bronzes cast on China's central plain, belonged to a steppe tradition (Mei 2009). The knife can be compared with one from the Elunino culture in the Russian Altai, and with its relatives at Shimao (Figure 4). Jade sceptres excavated at Erlitou (Figure 5: left) are copies of similar jades from Shimao. Hitherto unremarked is a significant trait of the Erlitou jades: many of them feature small projecting teeth (Figure 5). These jades have always been regarded as major products of Erlitou's central-Chinese tradition (Guojia wenwuju 2009: 156-57). Neat projecting teeth are, however, a hallmark of ornaments from Shimao, and are also found on similar bronze ornaments in the Yenisei Valley, south (C) Antiquity Publications Ltd, 2017 


\section{Shimao and Erlitou}
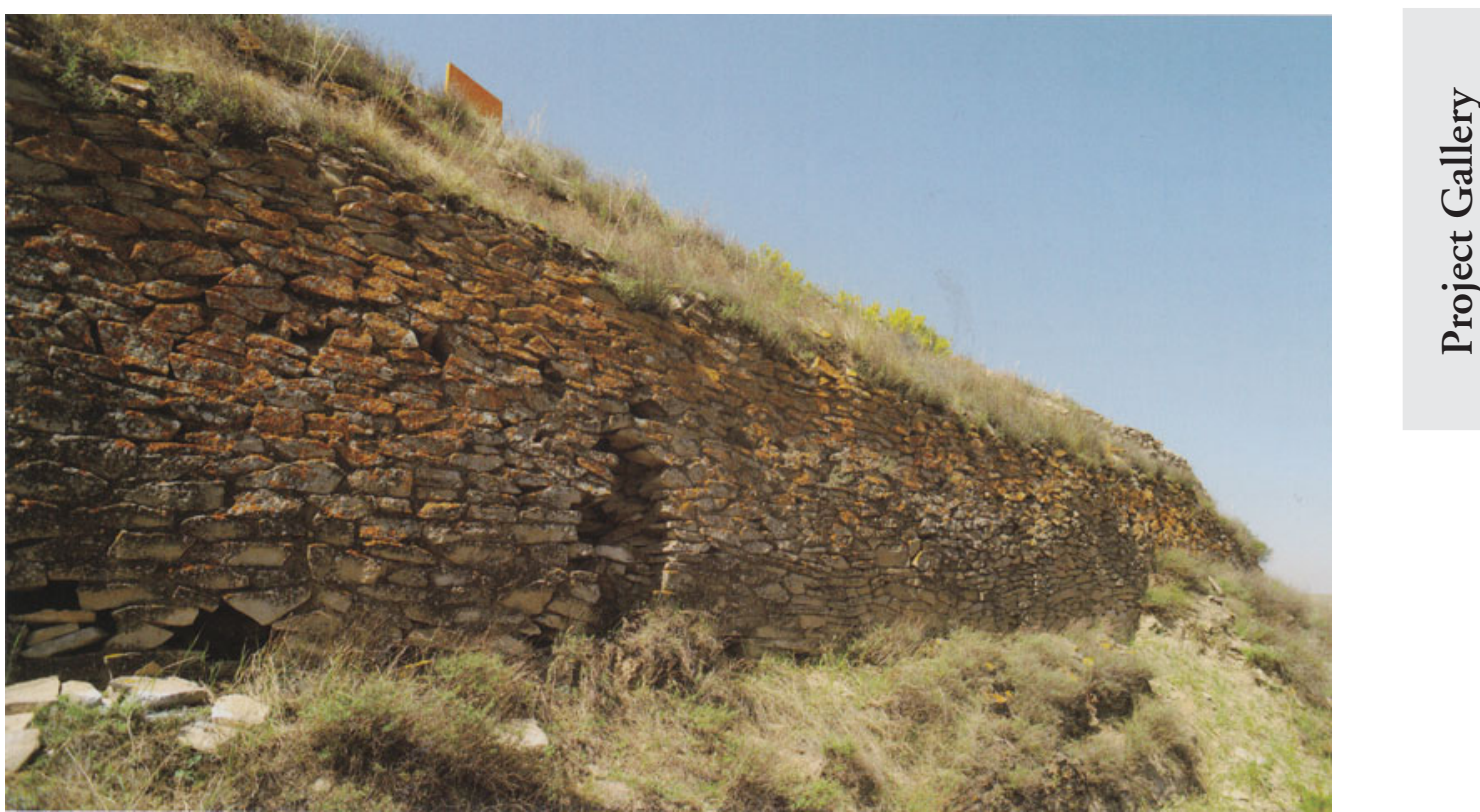

Figure 2. One of the major retaining walls at Shimao, after Faxian Shimao gucheng, p. 37 (upper figure).

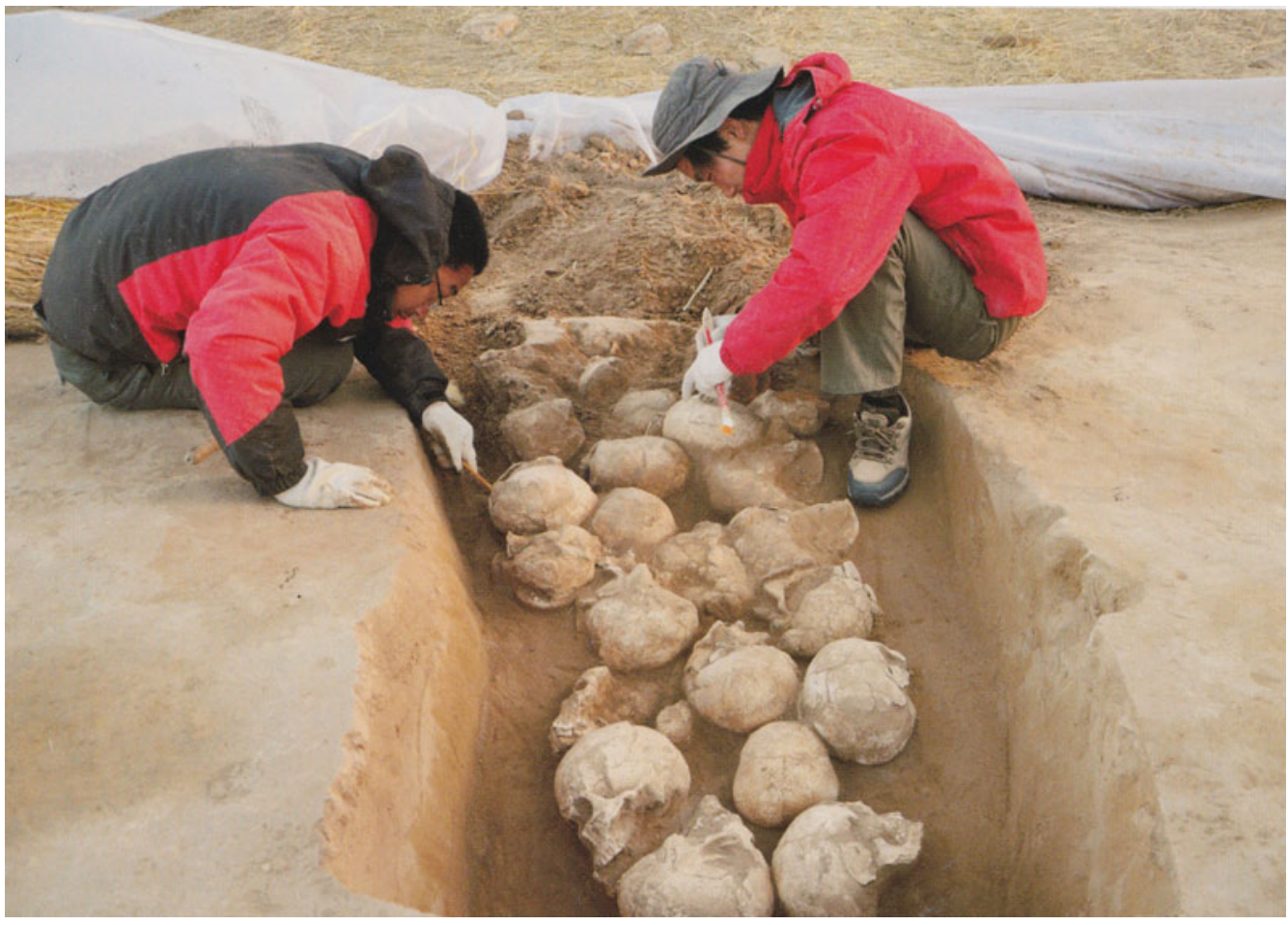

Figure 3. Detail of skull-pit 2 at Shimao, after Faxian Shimao gucheng, p. 113 (upper figure). 


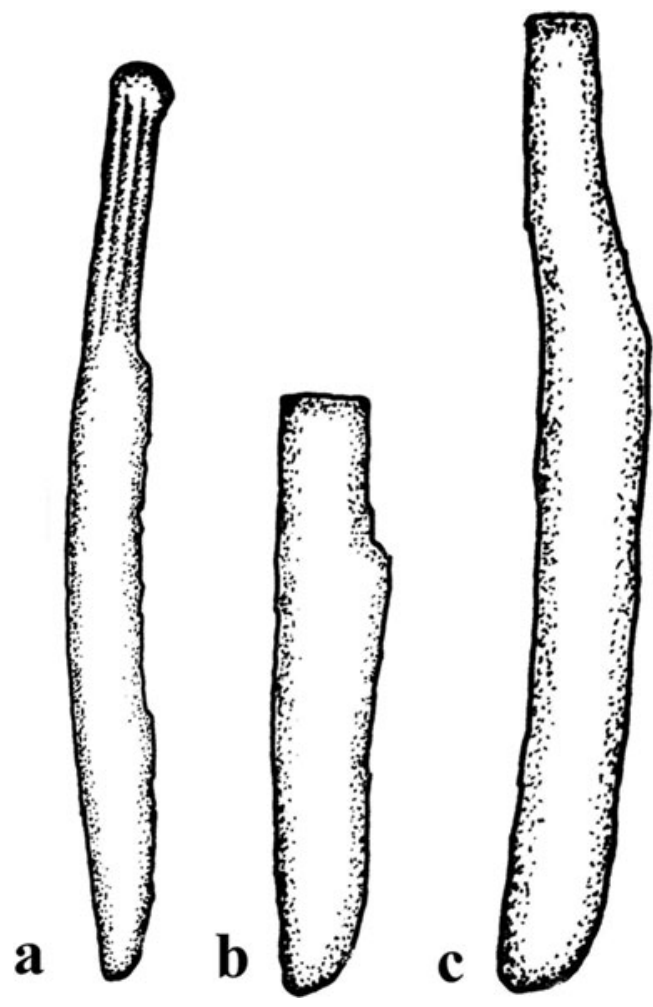

Figure 4. Drawing of three single-edged knives: a) of the Elunio culture, 2000-1800 BC, Russian Altai, length around $220 \mathrm{~mm}$; b) from Shimao, 2000-1800 BC, length around $100 \mathrm{~mm}$, see http://news.xinhuanet.com/politics/ 2017-01/11/c_1120285032.htm; c) Erlitou, 1700-1600 $B C$, length around $255 \mathrm{~mm}$ (drawing by John Rawson).
Siberia (Figure 6a \& b). Such similarities were probably the consequence of a shared culture across the steppe and into the northern regions of the Loess Plateau, rather than of direct contact. A similar ornament from Taosi (Figure 6c), which has puzzled excavators, can now be identified as a version of the ones from Shimao, or even an import brought by people from Shimao moving south. Personal ornaments in bronze were not at any stage popular in early central China, where jade was preferred. Therefore, it is not surprising that at Erlitou, and later at Shang sites, the bronzes were not adopted, but instead, small projecting teeth were taken over from the bronzes to enhance ceremonial jades (Figure 5).

These comparisons join together the steppe, Shimao, Taosi and Erlitou. Thus, we here recognise that one of the routes by which Erlitou gained bronze technology was precipitated by climate change, which first brought more people to Shimao, and then, as a colder dry spell made agriculture difficult, drove bronze-using

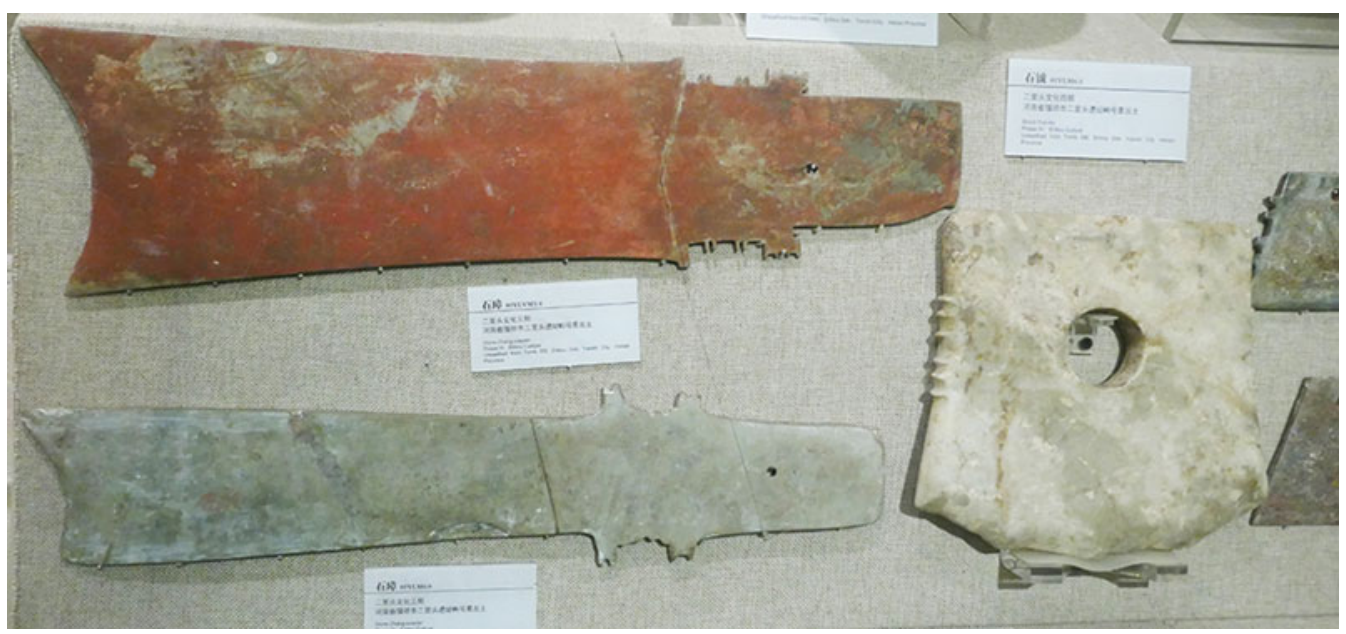

Figure 5. A group of jades excavated at Erlitou, all with small projecting teeth: (eft) two sceptres; centre) an axe; right) the edges of two reaping knives. Institute of Archaeology, Chinese Academy of Social Science, Beijing (author's photograph).

(C) Antiquity Publications Ltd, 2017 
peoples south, first to Taosi and then to Erlitou. It has long been accepted that the much earlier use of bronze in the steppe must have contributed to the development
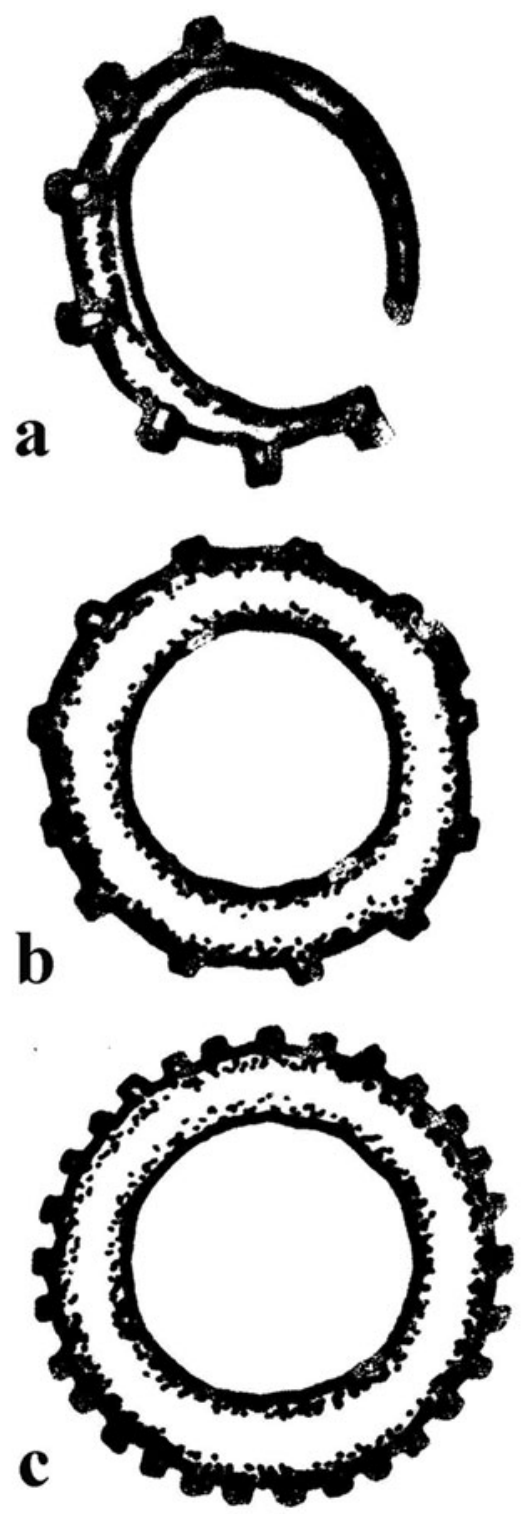

Figure 6. Drawing of three bronze ornaments: a) Karasuk culture c. 1400-1200 BC, diameter around $100 \mathrm{~mm}$ Abakan Museum; b) Shimao 2000-1800 BC, diameter around $120 \mathrm{~mm}$, private museum in Shenmu; c) excavated at Taosi, diameter around $125 \mathrm{~mm}$ Shanxi province (drawing by John Rawson). of China's production and use of bronze. The finds from Shimao now provide direct evidence of one of the most probable sources of this revolutionary change.

\section{Acknowledgements}

The visit to Shimao was organised by the Shaanxi Provincial Institute of Archaeology. The author is grateful for the invitation to Shimao, and for the work of Sun Zhouyong and his colleagues. I am grateful for the assistance of Xiaojia Tang, who accompanied me to Shimao. The visit to Abakan Museum was organised by Yuri Esin.

\section{References}

Guojia wenwuju. 2009. Zaoqi Zhongguo, Zhonghua wenming qiyuan. Beijing: Wenwu chubanshe.

Hu, S., Z. Pengcheng \& Y. Ming. 2008. Yulin Huoshiliang yizhi dongwu yicun yanjiu. Renleixue xuebao 3: 232-48.

Liu, B., H. Jin, L. Sun, Z. Sun, Q. Niu, S. Xie \& G. LI. 2014. Holocene moisture change revealed by the $\mathrm{Rb} / \mathrm{Sr}$ ratio of aeolian deposits in the southeastern Mu Us Desert, China. Aeolian Research 13: 109-19. http://dx.doi.org/10.1016/j.aeolia.2014.03.006

MeI, J.J. 2009. Early metallurgy in the Eurasian Steppe and China: some challenging issues, in J.J. Mei \& T. Rehren (ed.) Metallurgy and civilization: Eurasia and beyond: 9-16. London: Archetype.

Peng, Y.J., J. Xiao, T. Nakamura, B. Liu \& Y. INOUCHI. 2015. Holocene East Asian monsoonal precipitation pattern revealed by grain-size distribution of core sediments of Daihai Lake in Inner Mongolia of north-central China. Earth and Planetary, Science Letters 233: 467-79. http://dx.doi.org/10.1016/j.epsl.2005.02.022

Shaanxi (ed.). 2016. Faxian Shimao gucheng. Beijing: Wenwu chubanshe.

Taosi (ed.). 2015. Xiangfen Taosi, 1978-1985 nian kaogu fajue baogao. Beijing: Wenwu chubanshe.

Wang, X.Y. \& G.H. Zhang. 2016. Xing xian Bi cun Longshan shidai yicun chutan. Kaogu yu wenwu 4 : 80-87.

Zhang, Z., J. Xu \& J. Qin. 1999. Zhongguo wenwu dituji: Shaanxi fence. Xi'an: Ditu chubanshe. 